\title{
Fuzzy Goal Programming Techniques for Production Planning in Industry
}

\author{
A.K. Bhargava \\ Department of Mathematics, \\ M.M.H College, Ghaziabad \\ (UP), \\ Affiliated: C.C.S. University, \\ Meerut (U.P.) India
}

\author{
S.R. Singh \\ Department of Mathematics, \\ D.N. College, Meerut (UP), \\ Affiliated: C.C.S. University, \\ Meerut (U.P.) India
}

\author{
Divya Bansal \\ Institute of Management \\ Studies, Ghaziabad (UP) \\ (Research Scholar, Banasthali \\ University, Rajasthan, India)
}

\begin{abstract}
This paper presents the production planning problem in industry with different operational constraints, including strategic aim of the company, profit goal, limit on finishing and furnace hours needed, cups manufactured with target values being imprecise in nature. The fuzzy goal programming techniques is applied to maximize the production capacity, maximize the profit, minimize the extra finishing labor and furnace hours, and ensure the manufacturing capacity. The objective of this paper is to elaborate a plan which takes manager's preferences into account. The results illustrate the flexibility of the proposed model by adjusting goal priorities with respect to importance of each objective and the aspiration level with respect to desired target values. LINDO 14.0 optimizer solver is used to draw results of the problem.
\end{abstract}

Keywords: Goal Programming, Production Planning, Fuzzy Goal Programming, Satisficing.

\section{INTRODUCTION}

The production planning problems involves objectives as to either maximize profit or minimize cost and is formulated to a single-objective function in linear programming. But in real life there are multiple objectives involved with imprecise target values. In order to design an efficient production planning system, a good understanding of the environment in terms of customers, products and manufacturing processes is a must [16]. Production planning is a complicated task that requires cooperation among multiple functional units in any organization. Therefore, new tools for production planning are required that consider these issues. To achieve this, in this paper, a fuzzy goal programming technique is used to determine optimal production plans.

With fast computational growth [8], both linear and non-linear goal programming can be solved using welldeveloped software such as Linear Interactive and Discrete Optimization (LINDO, 2011) or meta-heuristics such as simulated annealing, genetic algorithms, tabu search and so on [10].

Goal programming (GP), was developed by Charnes and Cooper [1]. Lee [11] applied the goal programming approach to production planning and then to aggregate production planning. Ghosh et al. [4] presents a goal programming technique for nutrient management by determining the optimum fertilizer combination for rice production. Tamiz et al. [18] have studies the modeling approach of goal programming does not attempt to maximize or minimize the objective function directly as in the case of conventional linear programming. Instead of that the goal programming (GP) model seeks to minimize the deviations between the desired goals and the actual results to be obtained according to the assigned priorities. Dantzig [2, 3] developed linear programming under uncertainty and also provided solution of two-stage linear programs with uncertainty called as the stochastic programming. In stochastic programming, the parameters are random variables with known distribution. The use of fuzzy set theory in GP was first considered by Narasimhan [13, 14, 15], Hannan [5, 6, 7], Ignizio [9]. Rubin and Narsimhan [17] and Tiwari et al. $[19,20]$ have investigated various aspects of decision problem using FGP. An extensive review of these papers is given by Tiwari et al. in 1985 .

\section{FUZZY GOAL PROGRAMMING}

The simple additive model in conventional GP for $\mathrm{m}$ goals

$G_{i}(x)$ with deviational variables $d_{i}^{+}, d_{i}^{-}$is defined as 


$$
\begin{gathered}
\operatorname{Minimize} \sum_{i=1}^{m}\left(d_{i}^{+}+d_{i}^{-}\right) \\
d_{i}^{+} \cdot d_{i}^{-}=0, \\
d_{i}^{+}, d_{i}^{-}, x \geq 0, i=1,2, \ldots, m,
\end{gathered}
$$

where $g_{i}$ represents the aspiration level of the $\mathrm{i}$-th goal.

\subsection{Fuzzy Goal Programming Model}

Now, further consider the FGP problem formulated as: Find $\mathrm{X}$

To satisfy $G_{i}(X) \% g_{i}, i=1,2, \ldots, m,(2)$

Subject to

$$
\begin{aligned}
& A X \leq b \\
& X \geq 0,
\end{aligned}
$$

where $\mathrm{X}$ is an n-vector with components $x_{1}, x_{2}, \ldots, x_{n}$ and $A X \leq b$ are $\quad$ system constraints in vector notation. The symbol ' $\gtrsim$ 'refers to the fuzzification of the aspiration level (i.e., approximately greater than or equal to). The i-th fuzzy goal $G_{i}(X) \% g_{i}$ in (2) signifies that the DM is satisfied even if less than the $g_{i}$ upto certain tolerance limit is attained. A linear membership function $\mu_{i}$ for the i-th fuzzy goal $G_{i}(X) \% \circ g_{i}$ can be expressed according to Zimmermann [21, 22] as

$$
\mu_{i}=\left\{\begin{array}{cl}
1 & \text { if } G_{i}(X) \geq g_{i} \\
\frac{G_{i}(X)-L_{i}}{g_{i}-L_{i}} & \text { if } L_{i} \leq G_{i}(X) \leq g_{i} \\
0 & \text { if } G_{i}(X) \leq L_{i}
\end{array}\right.
$$

where $L_{i}$ is the lower tolerance limit for the fuzzy goal $G_{i}(X)$. In case of the goal $G_{i}(X)^{\wedge} g_{i}$, the membership function is defined as
$\mu_{i}=\left\{\begin{array}{cl}1 & \text { Subject to } \mathrm{G}_{i}(x)+d_{i}^{-}-d_{i}^{+}=g \\ \frac{U_{i}-G_{i}(X)}{U_{i}-g_{i}} & \text { if } g_{i} \leq G_{i}(X) \leq U_{i} \\ 0 & \text { if } G_{i}(X) \geq U_{i}\end{array}\right.$ where $U_{i}$ is the upper tolerance limit.

The additive model of the FGP problem (2) is formulated by adding the membership functions together as

$$
\operatorname{Maximize} \mathrm{V}(\mu)=\sum_{i=1}^{m_{1}} \mu_{i}+\sum_{j=m_{2}}^{m} \mu_{j}
$$

Subject to

$$
\mu_{i}=\frac{G_{i}(X)-L_{i}}{g_{i}-L_{i}}
$$

$$
\mu_{j}=\frac{U_{j}-G_{j}(X)}{U_{j}-g_{j}}
$$

$$
\begin{aligned}
& A X \leq b, \\
& \mu_{i}, \mu_{j} \leq 1 ; i=1,2, \ldots, m_{1}, j=m_{1}, \ldots, \mathrm{m}, \\
& X, \mu_{i}, \mu_{j} \geq 0, i=1,2, \ldots, m_{1}, j=m_{1}, \ldots, \mathrm{m}
\end{aligned}
$$

where $\mathrm{V}(\mu)$ is called the fuzzy achievement function or fuzzy decision function.

The weighted additive model is widely used in GP and multiobjective optimization techniques to reflect the relative importance of the goals/objectives. In this approach the DM assigns differential weights as coefficients of the individual terms in the simple additive fuzzy achievement function to reflect their relative importance, i.e., the objective function is formulated by multiplying each together. This leads to the following formulation, corresponding to (4):

Maximize $\mathrm{V}(\mu)=\sum_{i=1}^{m_{1}} w_{i} \mu_{i}+\sum_{j=m_{2}}^{m} w_{j} \mu_{j}$

Subject to 


$$
\begin{aligned}
& \mu_{i}=\frac{G_{i}(X)-L_{i}}{g_{i}-L_{i}}, \\
& \mu_{j}=\frac{U_{j}-G_{j}(X)}{U_{j}-g_{j}}
\end{aligned}
$$

$$
\begin{aligned}
& A X \leq b \\
& \mu_{i}, \mu_{j} \leq 1 ; i=1,2, \ldots, m_{1}, j=m_{1}, \ldots, \mathrm{m}, \\
& X, \mu_{i}, \mu_{j} \geq 0, i=1,2, \ldots, m_{1}, j=m_{1}, \ldots, \mathrm{m},
\end{aligned}
$$

where $w_{i}$ is the relative weight of the $\mathrm{i}$-th fuzzy goal, $w_{j}$ is the relative weight of the $\mathrm{j}$-th fuzzy goal.

\section{PRODUCTION PLANNING PROBLEM}

Let us consider a problem proposed by Jones and Tamiz (2010) where a company produces three types of cups, termed grade A, grade B and grade C. Each grade A cup requires $2 \mathrm{hr}$ of furnace time and $3 \mathrm{hr}$ of finishing labor. Each grade B cup requires $3 \mathrm{hr}$ of furnace time and $5 \mathrm{hr}$ of finishing labor. Each grade $\mathrm{C}$ cup requires $4 \mathrm{hr}$ of furnace time and $10 \mathrm{hr}$ of finishing labor. A grade A cups yields a profit of $£ 1.00$, a grade B cup a profit of $£ 1.50$, and a grade $\mathrm{C}$ cup a profit of $£ 2.20$. The company currently has $1000 \mathrm{hr}$ of furnace time and $2000 \mathrm{hr}$ of finishing labor per day. They have a high level of demand and therefore they have a strategic aim of increasing production to 1000 cups per day by increasing the level of furnace and finishing hours available. The company wants to achieve the following goals:

Goal 1: Achieve the strategic aim of 1000 cups per day.

Goal 2: Achieve a profit of at least $£ 1250$.

Goal 3: Minimize the extra finishing and furnace hours needed.

Goal 4: Ensure that at least 300 of each type of cup is manufactured.

with the relative preference weights attached to all the goals as given below in Table 1:

Table 1: Preference weight

\begin{tabular}{|c|c|c|}
\hline $\begin{array}{c}\text { S. } \\
\text { No. }\end{array}$ & Goal & $\begin{array}{c}\text { Preference } \\
\text { weight }\end{array}$ \\
\hline 1. & $\begin{array}{c}\text { Achieve the strategic aim of } \\
1000 \text { cups per day }\end{array}$ & 5.0 \\
\hline 2. & $\begin{array}{c}\text { Achieve a profit of at least } \\
£ 1250\end{array}$ & 3.0 \\
\hline
\end{tabular}

\begin{tabular}{|c|c|c|}
\hline 3. & $\begin{array}{c}\text { Minimize the extra finishing and } \\
\text { furnace hours needed }\end{array}$ & 2.0 \\
\hline 4. & $\begin{array}{c}\text { Ensure that at least } 300 \text { of each } \\
\text { type of cup is manufactured }\end{array}$ & 1.0 \\
\hline
\end{tabular}

Assuming these goals to be fuzzy in nature, let the tolerance limit of four goals be $(\mathbf{8 0 0}, 1100,2550,5200$, 280, 265, 260).

\section{FORMULATION OF THE PROBLEM}

Let

$\mathrm{x}_{1}=$ Number of cups of grade A produced per day

$\mathrm{X}_{2}=$ Number of cups of grade $\mathrm{B}$ produced per day

$\mathrm{x}_{3}=$ Number of cups of grade $\mathrm{C}$ produced per day

Goals:

(i) Strategic aim of the company:

The company has the strategic aim of achieving 1000 cups per day which is assumed fuzzy in nature with the tolerance limit of 800 cups per day.

$$
\mathrm{x}_{1}+\mathrm{x}_{2}+\mathrm{x}_{3} \gtrsim 1000
$$

(ii) Profit goal:

The company desires to achieve a profit of at least $£ 1250$ with the tolerance limit of $£ 1100$.

$$
\mathrm{x}_{1}+1.5 \mathrm{x}_{2}+2.2 \mathrm{x}_{3} \gtrsim 1250
$$

(iii) Limit on finishing and furnace hours needed: The company wants to limit the finishing and furnace hours to 1000 hours of furnace time and 2000 hours of finishing labor per day with the tolerance limit of 2550 and 5200, respectively.

$$
\begin{aligned}
& 2 \mathrm{x}_{1}+3 \mathrm{x}_{2}+4 \mathrm{x}_{3} \lesssim 1000 \\
& 3 \mathrm{x}_{1}+5 \mathrm{x}_{2}+10 \mathrm{x}_{3} \leq 2000
\end{aligned}
$$

\section{(iv) Cups manufactured:}

Company desires to manufacture at least 300 of each type of cup, again, assumed to be fuzzy in nature with the tolerance limit of $(280,265,260)$.

$$
\begin{aligned}
& \mathrm{x}_{1} \gtrsim 300 \\
& \mathrm{x}_{2} \gtrsim 300 \\
& \mathrm{x}_{3} \gtrsim 300
\end{aligned}
$$

\subsection{Fuzzy Goal Programming Problem is formulated as:}




$$
\begin{aligned}
& \text { Maximize } \frac{5}{11} \mu_{1}+\frac{3}{11} \mu_{2}+\frac{2}{11}\left(\mu_{3}+\mu_{4}\right) \\
& +\frac{1}{11}\left(\mu_{5}+\mu_{6}+\mu_{7}\right)
\end{aligned}
$$

Subject to

$$
\begin{aligned}
& \mu_{1}=\frac{\left(x_{1}+x_{2}+x_{3}\right)-800}{1000-800} \\
& \mu_{2}=\frac{\left(x_{1}+1.5 x_{2}+2.2 x_{3}\right)-1100}{1250-1100} \\
& \mu_{3}=\frac{2550-\left(2 x_{1}+3 x_{2}+4 x_{3}\right)}{2550-1000} \\
& \mu_{4}=\frac{5200-\left(3 x_{1}+5 x_{2}+10 x_{3}\right)}{5200-2000} \\
& \mu_{5}=\frac{x_{1}-280}{300-280} \\
& \mu_{6}=\frac{x_{2}-265}{300-265} \\
& \mu_{7}=\frac{x_{3}-260}{300-260} \\
& \mathrm{x}_{\mathrm{i}}, \mu_{\mathrm{j}} \geq 0(\mathrm{i}=1,2,3 ; \mathrm{j}=1,2, \ldots, 7) \\
& 0 \leq \mu_{\mathrm{j}} \leq 1
\end{aligned}
$$

\begin{tabular}{|c|c|c|c|c|}
\hline & & $\begin{array}{l}\text { limit of } \\
1100\end{array}$ & & \\
\hline 3 & $\begin{array}{l}\text { Minimize } \\
\text { extra } \\
\text { finishing and } \\
\text { furnace hours }\end{array}$ & $\begin{array}{l}\text { Tolerance } \\
\text { limit of } \\
2550 \\
\text { Tolerance } \\
\text { limit of } \\
5200\end{array}$ & Partial & 2396 \\
\hline 4 & $\begin{array}{l}\text { No. of cups } \\
\text { manufactured }\end{array}$ & $\begin{array}{l}\text { A } \\
\text { Tolerance } \\
\text { limit of } \\
280 \\
\text { B - } \\
\text { Tolerance } \\
\text { limit of } \\
265 \\
C \\
\text { Tolerance } \\
\text { limit of } \\
260\end{array}$ & $\begin{array}{l}\text { Partial } \\
\text { Partial }\end{array}$ & $\begin{array}{l}280.5 \\
265\end{array}$ \\
\hline
\end{tabular}

\subsection{Computational Results}

Using the data presented, the proposed weighted fuzzy goal programming model is tested using LINDO [12] software package and the results are shown in Table 2:

$$
\begin{aligned}
& \mathrm{x}_{1}=280.5, \mathrm{x}_{2}=265, \mathrm{x}_{3}=260 \\
& \mu_{1}=0.0275, \mu_{2}=1, \mu_{3}=0.099, \\
& \mu_{4}=0.135, \mu_{5}=0.025, \mu_{6}=0, \mu_{7}=0 .
\end{aligned}
$$

Table 2: Interpretation of the Results

\begin{tabular}{|l|l|l|l|l|}
\hline Goal & Description & $\begin{array}{l}\text { Fuzzy } \\
\text { Target } \\
\text { Level }\end{array}$ & Satisfied & $\begin{array}{l}\text { Achieved } \\
\text { Value }\end{array}$ \\
\hline 1 & Strategic aim & $\begin{array}{l}\text { Tolerance } \\
\text { limit of } \\
800\end{array}$ & Partial & $\begin{array}{l}805.5\left(\mathrm{x}_{1}\right. \\
\left.+\mathrm{x}_{2}+\mathrm{x}_{3}\right)\end{array}$ \\
\hline 2 & Profit & Tolerance & Yes & 1250 \\
\hline
\end{tabular}

WwW.ijcat.com

\section{CONCLUSION}

In this paper, we have solved the production planning problem through the weighted fuzzy goal programming (WFGP) technique representing the relative importance of each goal. Two major objectives with imprecise target values are optimized through fuzzy goal programming. The goals are relatively balanced by different goal programming variants. The similar technique could be used for short-term and intermediate production planning in other continuous process industries. The number of fuzzy goals can be increased based on the decision maker's desirability.

\section{REFERENCES}

[1] Charnes, A. and Cooper, W. W. 1961. Management Models and Industrial Application of Linear Programming. Vol. I, John Wiley \& Sons, Inc., New York.

[2] Dantzig, G. B. 1955. Linear programming under uncertainty, Management Science, 1, 197-206.

[3] Dantzig, G. B. and Mandansky, A. 1961. On the solution of two-stage linear programs under uncertainty, In I. J. Neyman, Editor, Proc. 4th Berkeley Symp. Math. Stat. Prob., 165-176.

[4] Ghosh, D., Sharma, D. K. and Mattison, D. M. 2005. Goal programming formulation in nutrient management for rice production in West Bengal. International Journal of Production Economics, 95, $1-17$. 
[5] Hannan, E. L. 1981. Linear programming with multiple fuzzy goals. Fuzzy sets and Systems, 6, 235-248.

[6] Hannan, E. L. 1981. On fuzzy goal programming, Decision Sci., 12, 522-531.

[7] Hannan, E. L. 1982. Contrasting fuzzy goal programming and fuzzy multicriteria programming. Decision Sci., 13, 337-339.

[8] Ignizio, J. P. 1983. A note on computational methods in lexicographic linear goal programming. Journal of the Operational Research Society, 34 (6), 539-542.

[9] Ignizio, J. P. 1982. On the (re)discovery of fuzzy goal programming. Decision Sci., 13, 331-336.

[10] Jones, D. and Tamiz., M. 2010. Practical Goal Programming. Springer.

[11] Lee, S. M. 1972. Goal Programming for Decision Analysis. 1st ed. Auerbach Publishers Inc., Philadelphia.

[12] LINDO System, Inc. 2011. LINGO Optimization Modeling Language (User Manual), Chicago, IL.

[13] Narasimhan, R. 1980. Goal programming in a fuzzy environment. Decision Sci., 11, 325-336.

[14] Narasimhan, R. 1981. On fuzzy goal programming-Some comments. Decision Sci., 12, $532-538$.

[15] Narasimhan, R. 1982. A geometric averaging procedure for constructing supertransitive approximation to binary comparison matrices. Fuzzy Sets and Systems, 8, 53-61.

[16] Olhager, J. and Wikner, J. 2000. Production planning and control tools. Production Planning and Control, 11(3), 210-222.
[17] Rubin, P. A. and Narasimhan, R. 1984. Fuzzy goal programming with nested priorities. Fuzzy Sets and Systems, 14, 115-129.

[18] Tamiz, M., Jones, D. and Romero, C. 1998. Goal programming for decision making: An overview of the current state-of-the-art. European Journal of Operational Research, 111, 569-581.

[19] Tiwari, R. N., Dharmar, S. and Rao, J. R. 1986. Priority structure in fuzzy goal programming. Fuzzy Sets and Systems, 19, 251-259.

[20] Tiwari, R. N., Rao, J. R. and Dharmar, S. 1985. Some aspects of fuzzy goal programming. International Symposium on Mathematical Modelling of Ecological Environmental and Biological Systems, Kanpur, India.

[21] Zimmermann, H.-J. 1976. Description and optimization of fuzzy systems, International. J. General Systems, 2, 209-215.

[22]Zimmermann, H.-J. 1978. Fuzzy programming and linear programming with several objective functions, Fuzzy Sets and Systems, 1, 45-55. 